\title{
O NEOLIBERALISMO, O BANCO MUNDIAL E A EDUCAÇÃO: ALGUNS APONTAMENTOS
}

\author{
Monica Fernanda Botiglieri ${ }^{1}$ \\ Luiz Bezerra Neto ${ }^{2}$ \\ Universidade Federal de São Carlos - UFSCar
}

\section{RESUMO}

Este texto surgiu na intenção de retomar parte da discussão construída durante o segundo semestre do ano de dois mil e treze, no contexto da disciplina oferecida aos alunos do curso de doutorado em Educação na UFSCar, "Teorias de Estado e políticas públicas para a educação". Tem como objetivo inicial tratar do que se conheceu por neoliberalismo, seu histórico e efetivação. Secundariamente, buscar-se-á perceber aproximações entre esta proposta teórica, política e ideológica e construções estabelecidas no campo da educação, pela instituição Banco Mundial.

Palavras-chave: Neoliberalismo; Banco Mundial; Educação.

\section{NEOLIBERALISM, THE WORLD BANK AND EDUCATION: SOME NOTES}

\begin{abstract}
This paper emerged in intention of bringing part of the discussion built during the second half of two thousand thirteen in the context of the subject offered to students from the doctoral course in Education at UFSCar "Theories about State and public policies for education". The initial objective is to discuss the neoliberalism, its history and effectiveness. Secondly, we try to discuss the relationship between the neoliberalism and ideas for education, more specifically the ones that came from the World Bank.
\end{abstract}

Keywords: Neoliberalism; World Bank; Education.

\section{O Neoliberalismo}

Iniciamos esta discussão a partir da retomada do que conhecemos por neoliberalismo, um fenômeno político e econômico nascido após a Segunda Guerra Mundial (1939-1945), especialmente na Europa e América do Norte, onde o capitalismo já se mostrava mais avançado. Dentre as principais bases para a compreensão desta teoria, estão os textos de Friedrich Hayek - O caminho da servidão (1944) e Milton Friedman Capitalismo e liberdade (1962). Acerca do primeiro, Anderson (1995) nos afirma que:

Foi uma reação teórica e política veemente contra o Estado intervencionista e de bem estar. [...] Trata-se de um ataque apaixonado contra qualquer limitação dos mecanismos de mercado por parte do Estado, denunciadas como uma ameaça letal à liberdade, não somente econômica, mas também política (ANDERSON, 1995, p.01).

Hayek, à época, dirigira seu discurso contra o Partido Trabalhista inglês, na intenção de formular e fortalecer um novo tipo de capitalismo, livre de regras e contrário à política de bem-estar europeia e ao "igualitarismo" que se instaurava. O referido autor 
acreditava que qualquer intervenção do estado poderia se constituir num caminho para o socialismo, modelo que ele acreditava que tolhia a liberdade dos indivíduos. Afirmava o mesmo:

Embora alguns dos maiores pensadores políticos do século XIX, como de Tocqueville e Lord Actoe, nos advertissem de que socialismo significa escravidão, fomos continuamente avançando em direção ao socialismo. E agora, tendo visto uma nova forma de escravidão manifestar-se diante de nós, já esquecemos de tal modo essa advertência que mal nos damos conta da possível relação entre as duas coisas. A tendência moderna ao socialismo não implica apenas um rompimento definitivo com o passado recente, mas com toda a evolução da civilização ocidental. [...] $\mathrm{O}$ individualismo tem hoje uma conotação negativa e passou a ser associado ao egoísmo. Mas o individualismo a que nos referimos, em oposição a socialismo e a todas as outras formas de coletivismo, não está necessariamente relacionado a tal acepção. [...] tem como características essenciais o respeito pelo indivíduo como ser humano, isto é, o reconhecimento da supremacia de suas preferências e opiniões, na esfera individual, por mais limitada que esta possa ser, e a convicção de que é desejável que os indivíduos desenvolvam dotes e inclinações pessoais (HAYEK, 2010, p. 39-40).

Inicialmente as ideias de Hayek não tiveram grande espaço, o que de acordo com Anderson (1995) deveu-se ao fato de que o capitalismo apresentava-se em avanço crescente, especialmente nas décadas de 1950 e 1960, quando os defensores desta nova organização afirmavam que as políticas de então, favorecendo o Estado de bem-estar e certa igualdade, não somente destruiriam a liberdade individual, mas acabariam com a livre concorrência e prosperidade da população, defendendo que a desigualdade era algo positivo e imprescindível aos sujeitos. Ainda segundo o autor, em 1973:

[...] quando todo o mundo capitalista avançado caiu numa longa e profunda recessão, combinando, pela primeira vez, baixas taxas de crescimento com altas taxas de inflação, mudou tudo. A partir daí as ideias neoliberais passaram a ganhar terreno. As raízes da crise, afirmavam Hayek e seus companheiros, estavam localizadas no poder excessivo e nefasto dos sindicatos e, de maneira mais geral, do movimento operário, que havia corroído as bases da acumulação capitalista com suas pressões reivindicativas sobre os salários e com sua pressão parasitária para que o Estado aumentasse cada vez mais os gastos sociais (ANDERSON, 1995, p.02).

Ao contrário, o modelo neoliberal que se construía trazia como base o individualismo, a auto responsabilização, com o argumento fundamental de defesa da liberdade. A esse respeito, Friedman (1962) apontava que a pátria não se constituiria por algo acima dos indivíduos, mas por eles próprios, declarando que o homem verdadeiramente livre não seria aquele preocupado com o que a pátria poderia oferecê-lo ou com o que ele próprio poderia oferecer à sua pátria, mas sim atento ao que o indivíduo, unido aos seus, poderia realizar junto ao governo a fim de alcançarem seus objetivos e responsabilizarem-se por seus atos, protegendo acima de tudo a liberdade. O governo, nesse sentido, cumpriria com o papel de preservar a liberdade, contudo, por tratar-se de instrumento de concentração de poder político, era também ameaça. O mesmo declara: 
Primeiro, o objetivo do governo deve ser limitado. Sua principal função deve ser a de proteger nossa liberdade contra os inimigos externos e contra nossos próprios compatriotas; preservar a lei e a ordem; reforçar os contratos privados; promover mercados competitivos. Além desta função principal, o governo pode, algumas vezes, nos levar a fazer em conjunto o que seria mais difícil ou dispendioso fazer separadamente. Entretanto, qualquer ação do governo nesse sentido representa um perigo. Nós não devemos nem podemos evitar usar o governo nesse sentido. Mas é preciso que exista uma boa e clara quantidade de vantagens, antes que o façamos. E contando principalmente com a cooperação voluntária e a empresa privada, tanto nas atividades econômicas quanto em outras, que podemos constituir o setor privado em limite para o poder do governo e uma proteção efetiva à nossa liberdade de palavra, de religião e de pensamento (FRIEDMAN, 1962, p.05).

Acerca do papel a ser exercido pelo Estado, Anderson (1995) ao discutir a concepção neoliberal colocava que esta tinha como determinação:

[...] manter um Estado forte, sim, em sua capacidade de romper o poder dos sindicatos e no controle do dinheiro, mas parco em todos os gastos sociais e nas intervenções econômicas. A estabilidade monetária deveria ser a meta suprema de qualquer governo. Para isso seria necessária uma disciplina orçamentária, com a contenção dos gastos com bem-estar, e a restauração da taxa "natural" de desemprego, ou seja, a criação de um exército de reserva de trabalho para quebrar os sindicatos. Ademais, reformas fiscais eram imprescindíveis, para incentivar os agentes econômicos. Em outras palavras, isso significava reduções de impostos sobre os rendimentos mais altos e sobre as rendas. Desta forma uma nova e saudável desigualdade iria voltar a dinamizar as economias avançadas [...] (ANDERSON, 1995, p. 02-03).

Assim, os defensores da proposta neoliberal afirmavam ser necessário evitar a centralização e fortalecimento de governos federais, que por sua vez acreditavam na maior efetividade desta prática no sentido de legislar propostas de interesse público e distribuição de riquezas. Asseguravam os ideólogos do neoliberalismo que este era um grande risco, posto que aqueles no poder poderiam exercer suas funções para a vontade ou não dos demais. Deste modo, limitar a possibilidade de centralização do poder a cargo do governo surgia, mais uma vez, como forma última de defesa da liberdade, além ainda, de argumentos como o de que grandes feitos da humanidade não foram construídos por governos centralizadores, mas por indivíduos genialmente corajosos, como Colombo, Newton, Einstein, etc. (FRIEDMAN, 1962).

Acreditava-se ainda que a liberdade econômica e política caminhassem juntas, na medida em que, para a obtenção da liberdade política, a liberdade econômica era importante, pois concentra ou dispersa poder. A liberdade econômica promoveria ainda a liberdade política:

Vista como um meio para a obtenção da liberdade política, a organização econômica é importante devido ao seu efeito na concentração ou dispersão do poder. $\mathrm{O}$ tipo de organização econômica que promove diretamente a liberdade econômica, isto é, o capitalismo competitivo, também promove a liberdade política porque separa o poder econômico do poder político e, desse modo, permite que um controle o outro. A 
evidência histórica fala de modo unânime da relação existente entre liberdade política e mercado livre. Não conheço nenhum exemplo de uma sociedade que apresentasse grande liberdade política e que também não tivesse usado algo comparável com um mercado livre para organizar a maior parte da atividade econômica (FRIEDMAN, 1962, p.09).

Ainda de acordo com Friedman, o capitalismo era a condição necessária para a liberdade política, no entanto, ele afirmava a existência de sociedades capitalistas que tinham como base de sua economia a empresa privada, sem no entanto organizarem livremente sua política, como o caso de experiências fascistas em diversos países.

Os teóricos desta proposta afirmavam ainda que uma sociedade de economia livre daria aos seus cidadãos aquilo que estes quisessem, atendendo aos seus anseios individuais e não aos de um grupo em particular. $O$ governo, não centralizador, teria suas responsabilidades reduzidas, corroborando para que cada um não precisasse se submeter aos desejos dos demais, mas pudesse, ao contrário, realizar aos seus próprios. Para ele,

Liberdade política significa ausência de coerção sobre um homem por parte de seus semelhantes. A ameaça fundamental à liberdade consiste no poder de coagir, esteja ele nas mãos de um monarca, de um ditador, de uma oligarquia ou de uma maioria momentânea. A preservação da liberdade requer a maior eliminação possível de tal concentração de poder e a dispersão e distribuição de todo o poder que não puder ser eliminado - um sistema de controle e equilíbrio. Removendo a organização da atividade econômica do controle da autoridade política, o mercado elimina essa fonte de poder coercitivo. Permite, assim, que a força econômica se constitua num controle do poder político, então num reforço (FRIEDMAN, 1962, p. 12).

De acordo com a teoria neoliberal, o maior uso do mercado viria a reduzir a tensão aplicada às decisões políticas, que necessitam por sua vez de concordância. Os defensores do neoliberalismo afirmam ainda que, quanto menor o número de questões que necessitem de aceitação, maior será a probabilidade de que tenhamos concordâncias e mantenhamos uma sociedade livre. Uma boa sociedade, nesse caso, seria aquela em que seus membros concordassem com algumas condições gerais, regras formuladas a todos, providas e reguladas pelo governo.

Vale ressaltar que embora os escritos de Hayek e Friedman datem das décadas de 1940 e 1960, o neoliberalismo não tornou-se hegemônico rapidamente, mas ao longo de anos, tendo sua grande oportunidade em 1979, com a eleição inglesa de Margaret Thatcher, a primeira governante disposta a aplicar o modelo neoliberal, seguida por Ronald Reagan nos Estados Unidos em 1980 e outros países como Alemanha, Dinamarca, que pouco a pouco elegeram governantes declaradamente dispostos a aderir ao projeto. Como parte de seu ideário, apresentava-se fortemente um anticomunismo compartilhado por grande parte dos países europeus e América do Norte. Segundo Anderson:

O ideário do neoliberalismo havia sempre incluído, como componente central, o anticomunismo mais intransigente de todas as correntes capitalistas do pós-guerra. O novo combate contra o império do mal - a servidão humana mais completa aos olhos de Hayek - inevitavelmente fortaleceu o poder de atração do neoliberalismo político, consolidando o predomínio da nova direita na Europa e América do Norte. Os anos 80 
viram o triunfo mais ou menos incontrastado da ideologia nesta região do capitalismo avançado (ANDERSON, 1995, p. 03).

Ainda segundo o autor, a efetivação deste modelo se erigiu de maneiras distintas, resultando que na Inglaterra deu-se de maneira sistemática e ambiciosa, na medida em que contraiu-se a emissão monetária, foram abolidos os controles sobre fluxos financeiros, gerou-se desemprego massivo, greves foram combatidas, criou-se legislação anti-sindical, cortaram-se gastos sociais e tiveram início as mais variadas privatizações. Já nos Estados Unidos, o regime neoliberal demonstrava intenções distintas, sobretudo no tocante à competição militar com a União Soviética, buscando derrubar sua economia e o então regime comunista na Rússia. Para além, também foram combatidas as greves trabalhistas e impostos foram reduzidos em favor dos mais ricos, no entanto, diferente do que era proposto ao modelo econômico neoliberal, não houve por parte do governo Reagan disciplina orçamentária e, segundo Anderson (1995), o país se lançou a uma "corrida armamentista sem precedentes, envolvendo gastos militares enormes, que criaram um déficit público muito maior do que qualquer outro presidente da história norte-americana" (ANDERSON, 1995, p.05).

Em outros países europeus, enquanto o neoliberalismo se fortalecia eram construídas propostas consideradas progressistas, voltadas a um governo de esquerda. Territórios como França e Grécia, entre o final da década de 1970 e início dos anos 1980, propunham políticas de redistribuição de renda e proteção social, contudo, em pouco tempo estes governos fracassaram e, fortemente influenciados pelos mercados internacionais, reorientaram suas políticas aproximando-se das práticas neoliberais, buscando especialmente a estabilidade monetária a partir de contenções em seu orçamento e concessões fiscais.

Gradativamente o neoliberalismo se fortalecia enquanto ideologia dominante, conquistando mesmo territórios antes declarados contra sua proposta política e econômica. Afirma-se que em muitos de seus propósitos ele triunfou, na medida em que recuperou lucros pela detenção da inflação, derrotou greves e movimentos sindicais, reduziu gastos sociais, salários, aumentou o desemprego e a "natural" desigualdade social que julgava ser necessária ao bom funcionamento da sociedade e dos mercados.

Contudo, Anderson (1995) coloca que o pensamento neoliberal tinha como principal intenção reanimar o capitalismo, de maneira que fossem restauradas altas taxas de crescimento, o que não aconteceu, tendo em vista que, ainda com todas as condições criadas pelos governos em favor do capital, grandes operações de investimentos financeiros reais pouco aconteceram, além do fato de que as políticas de bem-estar social, mesmo com inúmeras medidas contrárias, não diminuíram efetivamente. Os gastos com o desemprego e a parcela de aposentados foram altos, assim:

[...] embora o crescimento da proporção do produto nacional consumida pelo Estado tenha sido notavelmente desacelerado, a proporção absoluta não caiu, mas aumentou, de mais ou menos $46 \%$ para $48 \%$ do PNB médio dos países da $\mathrm{OCDE}^{3}$ durante os anos 80 (ANDERSON, 1995, p. 08).

Outra crise se apresentou em 1991, levando países como Inglaterra e Estados Unidos a níveis imensos de endividamento, o que justificaria em muitos casos o abandono à lógica neoliberal nesta década. Contudo, este não foi o ocorrido e mais uma vez suas propostas se fortaleceram, tanto nos países originários, quanto em outros, demonstrando imenso poder ideológico. Para além, enquanto deixava aparentes suas limitações nos países 
do ocidente, na Europa oriental e União Soviética o capitalismo neoliberal "triunfava" com o combate ao comunismo. Ainda com Anderson (1995), afirma-se que, à época, os governos do leste Europeu aderiram fortemente às reformas neoliberais, posicionando-se contrários às políticas de bem-estar social e quaisquer benefícios não atrelados a méritos e esforços individuais.

Assim, gradualmente as experiências neoliberais foram se multiplicando, alcançando no final da década de 1980 e início dos anos 1990 os países da América Latina e demonstrando-se ora mais, ora menos ortodoxos às proposições de Hayek ou Friedman.

Após esta breve retomada acerca da teoria neoliberal e algumas de suas experiências, buscar-se-á apresentar aqui possíveis aproximações entre sua lógica e a organização da instituição financeira Banco Mundial, bem como suas práticas no campo da educação. Espera-se demonstrar, ao término destes escritos, as influências da primeira sobre o último, ainda que inicialmente.

\section{O Banco Mundial, o neoliberalismo e a educação: possíveis aproximações}

O investimento em educação nos países da América Latina sempre esteve abaixo das necessidades, se pensarmos em uma educação que atenda a todos os cidadãos com a mesma qualidade. Nesse sentido, Cruz afirma que,

O atual contexto econômico evidencia uma situação de crise do sistema capitalista, frente ao qual os representantes do interesse do capital internacional, particularmente o Banco Mundial e o FMI, intervêm na organização política e econômica dos países em desenvolvimento, na perspectiva de expandir os interesses dos países hegemônicos por meio de políticas que visam à abertura comercial e financeira, a desregulamentação das relações trabalhistas e a diminuição do tamanho e do papel do Estado na sociedade (CRUZ, 2003, p.51).

Frente a esta realidade esperamos construir um breve histórico acerca do que é e como atua o Banco Mundial, além de apresentar pontualmente como se constituem algumas de suas ações no campo da educação.

Data de julho de 1944 a primeira Conferência Monetária e Financeira das Nações Unidas, realizada em Bretton Woods, no estado de New Hampshire, Estados Unidos. Ainda em meio aos conflitos da Segunda Guerra Mundial (1939-1945) "Representantes de 44 países aprovaram a criação do BIRD (Banco Internacional de Reconstrução e Desenvolvimento) e do FMI (Fundo Monetário Internacional), desempenhando funções complementares" (MARTINS, p. 02, 2005).

Segundo o acordo firmado, ao BIRD e FMI caberiam a assistência e auxílio para a reconstrução e desenvolvimento dos países participantes, especialmente por meio de empréstimos não comerciais a longo prazo para o setor privado.

Ao tratarmos de início sobre o papel estabelecido pelo Banco Mundial, Pereira (2010) nos coloca que:

O Banco age, desde as suas origens, ainda que de diferentes formas, como um ator político, intelectual e financeiro, e o faz devido à sua condição singular de emprestador, formulador de políticas, ator social e produtor e/ou veiculador de ideais em matéria de desenvolvimento capitalista, sobre o que fazer, como fazer, quem deve fazer e para quem 
fazer. Ao longo de sua história, o Banco sempre explorou a sinergia entre dinheiro, prescrições políticas e conhecimento econômico para ampliar sua influência e institucionalizar sua pauta de políticas em âmbito nacional, tanto por meio da coerção (influência e constrangimento junto a outros financiadores e bloqueio de empréstimos) como da persuasão (diálogo com governos e assistência técnica) (PEREIRA, 2010, p.29).

Ainda no tocante à criação do BM, Santos (2010) irá nos trazer que:

O Banco Mundial representou a importância de sua atuação na defesa dos interesses capitalistas internacionais à medida que passou a gerenciar a reestruturação econômica de países subdesenvolvidos ou em vias de desenvolvimento (Terceiro Mundo) - principalmente da América Latina - por meio da aplicação de programas de ajustamento estrutural, intervindo na formulação de políticas internas e na própria legislação desses países (SANTOS, 2010, p.01).

Segundo o mesmo autor, a reordenação dos países em via de desenvolvimento pelas grandes instituições financeiras implicou também na consolidação destes organismos no gerenciamento da economia global.

Entre os anos de 1968 e 1981 o BM teve em sua presidência Robert MacNamara, secretário de Defesa dos Estados Unidos, que iniciou uma fase de preocupações por parte da instituição para com a pobreza, entendendo, no entanto, que esta seria solucionada automaticamente pelo crescimento econômico, ocasionando assim melhores condições de vida aos sujeitos (CRUZ, 2003).

Atualmente o Banco Mundial tem sede em Washington e, de acordo com Martins (2005), se constitui por uma única presidência e um total de cinco instituições:

[...] BIRD, Cooperação Financeira Internacional (1956), Associação Internacional de Desenvolvimento (1960), Centro Internacional para Arbitragem de Disputas sobre Investimentos (1966) e Agência Multilateral de Garantia de Investimentos (1988) (MARTINS, 2005, p.03).

Seus empréstimos são realizados aos países integrantes do FMI e embora afirme em seus documentos que estes independem do regime político, países como Cuba, Brasil e Chile já passaram ou passam por restrições (em tempos de ditaduras militares, por exemplo). Há um grupo responsável pelas principais resoluções, formado por representantes dos Ministros das Finanças, entre outros que compõem os Estadosmembros, no entanto, a autora destaca que as decisões de fato são tomadas por apenas oito países:

[...] Alemanha, Arábia Saudita, China, Estados Unidos, França, Inglaterra, Japão e Rússia, detentores de uma cadeira permanente no Conselho de Diretores-executivos, composto por um total de 24. As demais nações, agrupadas em 16 blocos, elegem, a cada biênio, seus representantes. $\mathrm{O}$ voto é proporcional à contribuição monetária do país [...] em vez de respeitar o princípio "uma nação, um voto" que rege o sistema da Organização das Nações Unidas (ONU). Como maior acionista, 17,87\% das ações, o governo dos Estados Unidos decide as matérias importantes que requerem $85 \%$ dos votos, tem prerrogativa de 
veto e indica o presidente da instituição, tradicionalmente um norteamericano (MARTINS, 2005, p. 03).

Embora o discurso do Banco Mundial tenha se dado, ao longo dos anos, sob a égide de "alívio da pobreza", além de atenção a problemas ambientais e de discriminação da mulher, durante os anos 1950 sua atuação se deu em grande medida buscando a aproximação dos países então em vias de desenvolvimento, integrando-os ao mundo ocidental e, assim, afastando-os de qualquer "ameaça comunista" (MARTINS, 2005).

Tais agências tinham como perspectiva o desaparecimento da pobreza enquanto consequência de um possível crescimento econômico, porém, ao longo dos anos 1960 o que se podia perceber cada vez mais era que não só a pobreza não havia desaparecido, como a concentração de rendas e a miséria cresciam cada vez mais (SOARES, 2007).

Ao longo dos anos 1970, enquanto o mundo vivia uma situação de crise generalizada, os países mais industrializados iniciaram um processo de reestruturação tecnológica e produtiva, em meio a um ideário de globalização e inserção das teorias neoliberais, que formavam a base do Banco Mundial (embora o Brasil já se constituísse "parceiro" do BM, a reestruturação produtiva propriamente se apresentou fortemente em nosso país apenas nos anos 1990).

Na década de 70, com o acelerado processo de globalização da economia, as teorias monetaristas neoliberais passam a influenciar as economias, alcançando hegemonia nas décadas seguintes. Neste período, o Banco Mundial e o FMI passam a oferecer aparato ideológico e político para a expansão do neoliberalismo em escala mundial (CRUZ, 2003, p.58).

A instituição durante este período consolidou-se enquanto peça chave na sustentação e na adequação dos países em crise, passando a intervir cada vez mais fortemente nas políticas e ações destes, garantindo em troca inúmeros empréstimos. Por meio de tais ações o Banco Mundial colocava condições e ajustes em consonância com seus interesses, algo que se tornou mais claro nos anos 1980, quando os países financiados aderiram gradativamente ao neoliberalismo, dispostos a reduzir gastos públicos, abrir-se comercialmente, diminuir tarifas de importação/exportação, não restringir o ingresso de capital estrangeiro, eliminar intervenções do Estado e privatizar empresas e serviços públicos (SOARES, 2007).

Afirma-se ainda que:

Essas instituições responsabilizaram-se pelo monitoramento e pagamento das dívidas externas, assumindo o papel estratégico na reestruturação econômica dos países em desenvolvimento, garantindo a implantação de políticas de reajuste econômico e defendendo os interesses dos grandes credores internacionais.

Tal papel é explicitado na década de 80, quando o Banco Mundial passa a responsabilizar-se pelo fornecimento de aval para fontes de crédito internacional, por meio das condicionalidades, que vinculam os empréstimos e negociações à adequação das estruturas econômicas dos países devedores ao modelo neoliberal (CRUZ, 2003, p. 58).

A autora ainda retoma as proposições neoliberais construídas no Consenso de Washington, no ano de 1989, quando técnicos do BM, FMI e BID discutiam reformas necessárias junto a governantes dos EUA, a serem adotadas por países da América Latina. Segundo a mesma: 
As reformas expressas no Consenso de Washington espelham a retomada dos pressupostos liberais e das propostas debatidas por Friedrich August von Hayek em sua obra O caminho da servidão, publicada em 1944, em oposição às políticas do "Estado do Bem-Estar Social" difundidas no pósSegunda Guerra Mundial, sob o argumento de que todo tipo de intervenção estatal, além de ser um atentado às liberdades individuais, seria uma aproximação aos regimes totalitários e comunistas (CRUZ, 2003, p. 55).

$\mathrm{O}$ aceite das condições impostas pelo Banco Mundial não se deu da mesma maneira para todos os países e suas práticas, ao contrário do que propunham, geraram incontáveis críticas, na medida em que concentraram rendas nas mãos de poucos e colaboraram, em muitos casos, para a devastação do meio ambiente, financiando projetos fracassados nas áreas de energia, recursos florestais, entre outros com prejuízos milionários. Embora tenha proposto reajustes em seus planejamentos ainda na década de 1980, buscando restabelecer certa confiança e credibilidade diante de todo o mundo, suas ações voltadas à erradicação da pobreza e preservação ambiental pouco se efetivaram na prática.

Especificamente no tocante ao Brasil, a relação firmada com o Banco Mundial se apresentou ora mais próxima, ora conflituosa e com certo afastamento. Segundo Soares (2007) no período de 1976 a 1983 o número de investimentos em terras brasileiras cresceu consideravelmente, enquanto que na segunda metade da década decaíram os acordos, principalmente devido ao não cumprimento adequado do Brasil no que dizia respeito às condições que eram impostas pelo banco, além de problemas de ordem gerencial, o que causava o fracasso de muitos projetos.

Ao discutirmos as atuações de instituições como o Banco Mundial, é importante considerarmos que sua proposta principal era se constituir enquanto agência de desenvolvimento mundial, contudo, seus projetos e práticas de fato contribuíram e têm contribuído em muito para alargar as diferenças sociais, colaborando para o aumento da pobreza e da exclusão de milhares. Acerca das proposições que são apresentadas pela instituição, Soares (2007) nos aponta que estas tem sido no sentido de

[...] financiamento de programas sociais compensatórios voltados para as camadas mais pobres da população, destinados a atenuar as tensões sociais $[\ldots]$.

Ou seja, a recente ênfase no combate à pobreza tem um caráter instrumental onde os programas sociais visam garantir o suporte político e a funcionalidade econômica necessários ao novo padrão de crescimento baseado no neoliberalismo econômico (SOARES, 2007, p. 27).

Em nosso país a inserção das reformas neoliberais se deu em grande medida durante os governos de Fernando Collor de Mello (1990-1992) e Fernando Henrique Cardoso (1995-2002). Tal contexto colaborou para uma reaproximação entre Banco Mundial e o Brasil na década de 1990, no entanto, as mesmas consequências vivenciadas por outros países se apresentaram também aqui, com o aumento da dívida externa, queda no PIB per capita, além de quedas nos salários e aumento da população mais pobre (SOARES, 2007).

No tocante às políticas sociais, compreende-se que o Banco Mundial aproxima-se em grande medida das concepções neoliberais, remetendo ao mercado mesmo serviços essenciais, como saúde, educação, na crença de que todas as questões sociais devem-se ao pouco crescimento econômico e político dos países. Assim, formulam-se políticas 
compensatórias no sentido de aliviar a pobreza, sem em momento algum discutir fundamentos e causas estruturais das desigualdades, intrínsecas ao capitalismo (CRUZ, 2003).

Para além, associavam-se desde o início aos interesses do banco o papel do Estado mínimo, apenas como mantenedor de necessidades e funções essenciais, discussão posta também quando tratamos dos fundamentos do neoliberalismo. Em 1997, em seu relatório anual, o Banco Mundial apontava que:

Embora o Estado ainda tenha um papel central na provisão garantida de serviços básicos - educação, saúde e infraestrutura -, não é óbvio que deva ser o único provedor, ou mesmo que deva ser provedor. As decisões do Estado em relação à provisão, financiamento e regulamentação desses serviços devem basear-se nas vantagens relativas dos mercados, da sociedade civil e dos órgãos do governo. [...] O Estado tem muito a ver com a adoção pelos países de instituições sob as quais o mercado possa florescer. (BANCO MUNDIAL, 1997, p. 28; 30).

Cruz (2003) aponta ainda em seus escritos que, em períodos específicos de crise, faz-se necessária a apropriação de reivindicações dos trabalhadores, garantindo assim a manutenção de sua subalternidade. Para o BM, o Estado em crise e endividado deveria, primeiramente, estar empenhado em afastar-se de suas funções sociais, reajustar-se financeiramente, para só então retomar o funcionamento e fortalecimento de instituições públicas. Neste caso, para um tempo de reajuste e adequação fiscal, o ideal seria o repasse de demandas à iniciativa privada, aos cuidados do mercado. No que tange especificamente à educação:

[...] o discurso neoliberal resgata e reformula os enfoques economicistas da Teoria do Capital Humano, apontando a relação de dependência entre educação e desenvolvimento econômico e social, excluindo os fatores estruturais que determinam as diferenças de classe e enfatizando o valor do desempenho individual como determinante da condição de cada um na sociedade $[\ldots]$.

[...] o neoliberalismo propõe a transferência da lógica do mercado para a educação, elege a livre concorrência como fundamental para a garantia da eficiência e da qualidade dos serviços educacionais prestados e transfere a meritocracia vigente no campo empresarial para o educacional, pois assim estaria garantindo o estabelecimento de critérios competitivos, adequados para promover os mais capazes e esforçados (CRUZ, 2003, p. 66).

Assim, o Banco Mundial constrói como proposta aos países envolvidos um pacote de mudanças a serem realizadas, em reformas que, embora aleguem melhorias no acesso e qualidade escolar, visam na realidade reduções nos gastos públicos para com a educação. Dentre estas alterações, a autora aponta como exemplo a descentralização realizada por meio das municipalizações, que se efetivam em grande medida na distribuição de responsabilidade financeira e a responsabilidade, por parte do governo federal, apenas na criação de grandes diretrizes. Afirma-se então que este processo caracterizar-se-ia muito mais por uma desconcentração, imposta de cima para baixo, do que de fato por uma descentralização, ao contrário, de baixo para cima: 
[...] em geral, as propostas para a gestão educacional desenvolvidas no decorrer da década de 90 foram motivadas pelo poder central, normalmente sem um processo de consulta às demais esferas do sistema. O Banco Mundial afirma a necessidade de envolver pais e comunidade nos assuntos escolares, inclusive com a possibilidade de contribuição econômica para a sustentação da infra-estrutura, e parcerias com setor privado e ONGs. Além disso, quanto às orientações referentes ao financiamento da educação, sugere que as despesas sejam compartilhadas com as comunidades locais, por meio da inserção de cobranças de taxas para o ensino superior e o estabelecimento de empréstimos educativos para alunos carentes, que poderão reembolsar posteriormente os gastos realizados com educação (CRUZ, 2003, p.67).

Como parte das práticas levantadas pelo BM, exalta-se a ideia de autonomia, na crença de uma gestão progressista para as escolas, que buscam envolver a comunidade em sua organização, o que na realidade significa ao banco (e aos organizadores da educação de países que com ele cooperam) uma gradativa desresponsabilização do Estado. Diante deste afastamento, insere-se cada vez mais uma lógica pautada nas necessidades de mercado, tendo a educação enquanto produto e a escola como empresa, reforçando práticas de competitividade para o uso de dinheiro público e, conforme coloca Cruz (2003):

O Banco Mundial traça uma proposta educacional voltada aos interesses e necessidades do mercado de trabalho: daí a ênfase no ensino fundamental como fato relevante de retorno para o crescimento econômico do país, para melhoria da qualidade de vida e para a redução da pobreza. Entretanto, o Banco Mundial aponta que a demanda de educação no contexto de economia globalizada deve ser a formação que possibilite ao trabalhador o desenvolvimento da capacidade de aprender, para que este possa se adequar com facilidade às aceleradas transformações do mundo do trabalho (CRUZ, 2003, p. 68).

A educação constitui-se assim enquanto elemento de grande importância ao Banco Mundial e sua ideologia, na medida em que atende às necessidades de formação que são frutos das contradições criadas pelo próprio capitalismo. Há uma demanda social por educação, que se coloca dentre as práticas de alívio da pobreza, elevada em grande medida pelo afastamento do Estado e ajuste estrutural segundo ordens impostas pelo próprio banco. Para além, junto à educação e à escola, coloca-se o papel ideológico de globalização, que sufoca possíveis contestações à ordem vigente, voltando ao indivíduo a responsabilização por suas condições e sua situação de pobreza ou exclusão do mercado de trabalho e do consumo.

Em seus escritos Cruz (2003) aponta para alguns programas financiados pelo Banco Mundial na década de 1990 no Brasil, envolvendo o campo da educação. Estes não serão especificados aqui um a um, contudo, vale ressaltar que a autora chama a atenção para ajustes impostos aos estados participantes destes projetos, como por exemplo a redução do número de funcionários em relação ao número de alunos nas escolas públicas, exigência de compras por meio de licitações internacionais, além de forte estímulo à competição, por meio de repasse de verbas aos estados que apresentassem melhor gerenciamento de suas propostas.

A política de descentralização obriga as escolas a executarem ações até então sob a responsabilidade das secretarias de educação, como, por 
exemplo, o processo de licitação, compras e contratação de mão-de-obra para reformas. Esse procedimento envolve um volume considerável de recursos e uma complexidade adicional no processo de prestação de contas, visto as normas específicas do Banco Mundial (CRUZ, 2003, p.71).

Uma nova perspectiva de administração escolar, influenciada diretamente pelas propostas do Banco Mundial, repassa ainda mais encargos às escolas, responsáveis então por compras e contratação de serviços, organização e fiscalização de seus ambientes e toda a gestão de recursos, além é claro de suas funções já rotineiras, o que em grande medida pode apresentar-se como problema, tendo em vista que muitas vezes não se altera a estrutura do corpo escolar, o que acaba por exigir de gestores a priorização de determinadas tarefas a serem cumpridas, muitas das quais os afastando de questões importantes em âmbito escolar.

Assim, as intervenções de instituições como o Banco Mundial em meio educacional, colocadas como "acordos de cooperação", se efetivam de fato muito mais enquanto políticas convenientes aos interesses do capital internacional, que pela expansão dos preceitos neoliberais formam ideológica e tecnicamente a mão de obra necessária à sua própria manutenção. $\mathrm{O}$ Brasil tem se mostrado grande adepto aos projetos financiados e elaborados pelo banco, aderindo a propostas nas mais variadas áreas, como educação, saúde, habitação, entre tantas outras, o que nos destaca como país em vias de desenvolvimento e "parceiro" da instituição.

\section{Referências}

ANDERSON, Perry. Balanço do Neoliberalismo. In SADER, Emir \& GENTILI, Pablo (orgs.). Pós-neoliberalismo: as políticas sociais e o Estado democrático. Rio de Janeiro: Paz e Terra, 1995.

BANCO MUNDIAL. Relatório sobre desenvolvimento mundial: o Estado num mundo em transformação. Whashington / DC: Banco Mundial, 1997.

CRUZ, Rosana Evangelista da. Banco mundial e política educacional: cooperação ou expansão dos interesses do capital internacional?. Educar, Curitiba, n.22. p. 51-75, 2003. Editora UFPR.

FRIEDMAN, Milton. Capitalismo e Liberdade. 1962. Disponível em: http://www.institutoliberal.org.br/biblioteca/galeria/Milton\%20Friedman.htm. Acesso em: 20/01/2014.

HADDAD, Sérgio; TOMASSI, Lívia de; WARDE, Mirian Jorge (orgs.). O Banco Mundial e as Políticas Educacionais. São Paulo: Cortez, 2007

MARTINS, Mônica Dias (org.). O Banco mundial e a terra: ofensiva e resistência na América Latina, África e Ásia. São Paulo: Viramundo, 2004.

O Banco Mundial e as Políticas Públicas na América Latina. XXV Congresso da ALAS. Porto Alegre, 2005.

PEREIRA, João Márcio Mendes. O Banco Mundial como ator político, intelectual e financeiro - 1944 - 2008. Rio de Janeiro: Civilização Brasileira, 2010.

SANTOS, Flávio dos Reis. Banco Mundial e gerenciamento da educação brasileira. 2010. Disponível 
http://flavioreis.webnode.com.br/news/banco $\% 20$ mundial $\% 20 \mathrm{e} \% 20$ gerenciamento $\% 20 \mathrm{da}$ \%20educa\%C3\%A7\%C3\%A3o\%20brasileira/. Acesso em: 20/01/2014.

TEIXEIRA, Francisco José Soares. O neoliberalismo em debate. In TEIXEIRA, José Francisco Soares; ALVES, Giovani; NETO, José Meneleu \& OLIVEIRA, Manfredo Araújo de (orgs). Neoliberalismo e Reestruturação Produtiva - As novas determinações do mundo do trabalho. 2.ed. São Paulo: Cortez; Fortaleza: Universidade Estadual do Ceará, 1998.

\section{Notas}

${ }^{1}$ Doutoranda e Mestre em Educação pela Universidade Federal de São Carlos. Membro do Grupo de Estudos e Pesquisas sobre Educação do Campo - GEPEC/HISTEDBR.

${ }^{2}$ Professor do Departamento de Educação (DEd) da Universidade Federal de São Carlos e Coordenador do GEPEC/HISTEDBR

${ }^{3}$ Organização para a Cooperação e Desenvolvimento Econômico.

Recebido: $\quad$ julho/14 $\quad$ Aprovado: $\quad$ agosto/14 